\title{
Progress on the Engineering Ambassador Network: A Professional Develop- ment Organization with an Outreach Mission
}

\author{
Mr. Michael Alley, Pennsylvania State University, University Park
}

Michael Alley is an associate professor of engineering communication at Pennsylvania State University. $\mathrm{He}$ is the author of The Craft of Scientific Presentations, 2nd edition, and was a cofounder of the Engineering Ambassador Network.

Ms. Christine Haas, Engineering Ambassadors Network

Prof. Karen A. Thole, Pennsylvania State University, University Park

Dr. Karen A. Thole holds a Bachelors of Science and Masters of Science in Mechanical Engineering from the University of Illinois, and a Doctorate from the University of Texas at Austin. After receiving her PhD, she spent two years as a post-doctoral researcher at the Karlsruhe Institute of Technology in Germany. Her academic career began in 1994 when she became an Assistant Professor at the University of Wisconsin-Madison. In 1999, she accepted a position in the Mechanical Engineering Department at Virginia Tech where she was promoted to Professor in 2003 and was recognized as the William S. Cross Professor of Mechanical Engineering in 2005. In 2006, she was appointed and continues to hold the position of Head of the Department of Mechanical and Nuclear Engineering at The Pennsylvania State University. Dr. Thole has published over 180 peer-reviewed archival journal and conference papers and advised over 50 theses and dissertations. She founded the Experimental and Computational Convection Laboratory (ExCCL) which is a Pratt and Whitney Center of Excellence for heat transfer. She is a Fellow of ASME and serves as the Chair of the Board of Directors for the International Gas Turbine Institute, as the Chair of the ASME - ME Department Head Executive Committee, as a member of the Vision 2030 Committee, and as the Chair of ASME's Committee on Honors. She has been recognized by the U.S. White House Champion of Change for recruitment efforts in STEM and by Penn State's Rosemary Schraer Mentoring Award.

\section{Ms. Melissa Marshall, Pennsylvania State University, University Park Dr. Joanna K. Garner, Old Dominion University}

Dr. Garner is a Research Associate Professor in The Center for Educational Partnerships at Old Dominion University, VA. 


\section{Progress on the Engineering Ambassador Network: A Professional Development Group with an Outreach Mission}

\section{Introduction}

To solve today's engineering challenges, we need a wide range of solutions, which can be realized only by having enough engineers with diverse and strong technical backgrounds. Workforce studies have shown that the number of students being educated in STEM (science, technology, engineering, and math) cannot meet projected demands [1]. Also, the current enrollments in engineering are not diverse, especially among women, blacks, and Hispanics [2]. On a related issue, a recent survey of engineers in industry indicates a compelling need for engineers to have strong communication skills [3].

To address these challenges, Pennsylvania State University created the Engineering Ambassador Program: a professional development program for undergraduate engineering students with an outreach mission to middle and high schools. The development mission is to enrich the communication and leadership skills of engineering undergraduates through academic programs. The outreach mission of this Engineering Ambassador Program is to attract a diverse population of middle and high school students into engineering. In short, the Engineering Ambassador Program places the right messenger (engineering students with advanced presentation skills) with the right message (messages about engineering from Changing the Conversation [4]) in front of middle and high school students. In the past four years, these engineering ambassador presentations have received much praise, both from the 10,000 middle and high school students visited and from those students' teachers. Correspondingly, the Program at Penn State has grown in the past four years from 12 female ambassadors to 66 ambassadors, of whom more than two-thirds are from groups under-represented in engineering. Because of industry interest, the program has spread to a Network of four schools in the northeast: Rensselaer Polytechnic Institute, the University of Connecticut, and Worcester Polytechnic Institute. In August 2012, with an NSF workshop grant [5], the Network held an inaugural national workshop that trained pilot programs of 2-4 engineering ambassadors at 17 other geographically diverse institutions with the goal of further expanding the Network.

This paper describes progress on the expansion of the Network, which has two key goals: (1) developing an extended community to provide valuable communication and leadership skills to ambassadors and (2) creating an environment where ambassadors have more leverage and resources to increase the diversity of students entering engineering. The progress from the expansion includes results from two on-site workshops at pilot schools and a teacher training workshop in Atlanta - these workshops were made possible by support from ASME [6]. In addition, this coming year, the expansion is set to include five on-site workshops at additional 
pilot schools. These five workshops are supported by a four-year grant, beginning in summer 2013, from the National Science Foundation [7]. The main goal of these on-site workshops at the pilot institutions is to have those programs reach a critical mass of ambassadors and to provide the faculty on those campuses with the materials and training needed to sustain those programs.

In this paper, we first provide a more detailed justification of this project. Then we discuss background on the inaugural national workshop of 2012, what we accomplished in the year following the that workshop, what we are doing in our first year of our four-year Type II TUES Grant, and the greatest challenges that currently exist in this expansion.

\section{Justification for the Project}

Recently, President Obama placed more emphasis on our nation developing a strong workforce in the STEM fields. In his address to engineering deans and administration officials on February 8, 2012, President Obama, along with the Council on Jobs and Competitiveness, stated a goal of having at least a 10 percent increase in engineering graduates over the next decade, which amounts to 10,000 additional engineering graduates [8].

We are not diverse in our current engineering enrollments, and we are losing access to talented resources to help fill the workforce demands. The American Society of Engineering Education (ASEE) reports that in 2009 only 18.4 percent of engineering bachelor's degrees were awarded to women, 4 percent to black students, and 8.5 percent to Hispanic students [2]. Some disciplines are doing especially poor with regards to diversity. For example, electrical engineering, computer engineering, computer science, and mechanical engineering all bestow less than 12 percent of their bachelor degrees to women.

A challenge in developing a strong technical workforce lies in teaching professional skills to our engineering students. A recent survey of engineers working in industry indicates a compelling need for engineers to have strong communication skills [3]. While most engineering programs include communication in the curriculum, the types of communication taught are limited and often do not include training in public speaking to a range of audiences. This deficiency in communication skills further exacerbates a lack of public understanding, particularly by high school guidance counselors and teachers, on the career opportunities and the impacts of engineering. Given its breadth, engineering is not an easy profession to describe to a middle or high school student. Through no fault of their own, many school guidance counselors as well as science and math teachers cannot describe the impact that engineers have on our daily lives. For that reason, a need exists for the engineering profession to better express the importance of engineering to all middle and high school students so that a more diverse group will consider the profession.

In light of these challenges, a professional development program for engineering undergraduates was created at Penn State with a specific outreach mission. The professional 
development mission of this program, known as the Engineering Ambassador Program, is to enrich the communication and leadership skills of engineering undergraduates. The outreach mission of the Engineering Ambassadors is to attract a diverse population of middle and high school students into engineering. To increase the diversity, the Engineering Ambassador Program places the right messenger (undergraduate engineers with advanced communication and leadership skills) with the right message (marketing messages vetted by the National Academy of Engineering in their book Changing the Conversation [4] - engineers make a world of difference and engineers contribute to the health, happiness, and safety of our everyday lives) in front of middle and high school classes [5]. In addition, the Program empowers these undergraduate engineers by teaching them advanced engineering communication skills [10-11].

The expansion of the Engineering Ambassador Program from a Network of four member sites in the northeast to a Network of about 20 member sites across the United States (from Oregon to Maine) has the defined goal of increasing the diversity of students entering engineering, while providing valuable professional skills to undergraduate engineering students - skills that are required by industry for early career engineers. Through survey data, we have found that through the Engineering Ambassadors that increased confidence levels are achieved by the undergraduate engineering students in being able to speak of their passion for engineering to a wide range of audiences [9].

Given that several other institutions around the country have programs with the label "engineering ambassadors," one might question the need for an emphasis on the programs in the Engineering Ambassador Network. For instance, large "engineering ambassador" programs exist at North Carolina State [12], Purdue [13], Cornell [14], and Texas Tech [15]. However, three features distinguish the programs of the Engineering Ambassador Network discussed in this proposal. First, a major focus of the programs in the Engineering Ambassador Network is outreach to middle and high school students in off-campus events. In contrast, most other engineering ambassador programs are limited to on-campus events, such as tours for prospective students. Second, the Network schools use messages from Changing the Conversation as the foundation for their outreach presentations. Third, the Network schools provide formal training to their ambassadors on advanced communication skills and leadership skills.

We are uniquely positioned at this particular time to nationally scale the Engineering Ambassador Program, as illustrated in the following ways: (i) we have already demonstrated a successful pilot scale-up at three other institutions in the northeast; (ii) we held a successful national workshop in August 2012 with participation of 20 institutions, 19 of whom have expressed strong interest in being a part of a national network of Engineering Ambassadors; (iii) we received a strong endorsement by ASME, a professional society that intends to sustain the program for all engineering disciplines (not just mechanical engineers); and (iv) we have identified three highly qualified instructors willing to provide workshops to help initiate the Engineering Ambassador Programs at the institutions who have expressed interest. All three 
instructors have led training workshops for engineering ambassadors and are well-poised, given their experience and background, to run effective 2.5-day workshops at other campuses.

\section{Background on Inaugural National Workshop of August 2012}

Between 2010 and 2012, numerous faculty and department heads from across the United States inquired about the Engineering Ambassador Programs at Penn State, RPI, University of Connecticut, and WPI with the intention of emulating these programs at their own institutions. Given this interest, we requested and received support from the National Science Foundation to hold an inaugural national workshop [8] to disseminate information on how to start an engineering ambassador program (http://www.engineeringambassadors.org/) such as the ones existing at the Network schools.

The inaugural Engineering Ambassador National Workshop was hosted by Penn State on August 17-19, 2012. Coordinated by a team of faculty and students at Penn State, the workshop was directed by a steering committee with members from ASME, industry, and two other academic institutions. The program was advertised in ASEE's Prism, which has an international distribution. In addition, we used email listservs to send announcements through professional organizations, including ASME, IEEE, ASCE, SWE, and WEPAN. We also developed an informational website for the workshop: www.engr.psu.edu/ambassadors/workshop.

The goal of the inaugural workshop was to initiate pilot engineering ambassador programs at the attending institutions by training two to four engineering ambassadors from each of those attending institutions. In selecting participants, we wanted a diverse range of institutions with a high likelihood for success in scaling the pilot programs to full-fledged programs. The National Science Foundation funding was used to provide travel support and cover hotel and workshop costs for selected participants, with the goal of encouraging participation from a diverse range of schools across the country.

In addition to the four pilot schools, a total of 110 people from 17 institutions across the United States attended the 2.5-day workshop. At the core of this attendance were 40 engineering undergraduates and 55 faculty and administrators. As shown in Figure 1 and Table 1, we met our goal of achieving diversity, both in the type of institution and in the geography of the institutions. Also, as seen in the photo of participants, we achieved our goal in having a strong representation of groups historically under-represented in engineering (for example, 32 of the 40 newly trained engineering ambassadors were female). The workshop achieved the following outcomes:

1. All participants received an overview of the four existing engineering ambassador programs.

2. All new engineering ambassadors received presentation training, coaching, and multiple critique sessions, to help them leave with a successful presentation in hand for a high school visit. 
3. Faculty advisors discussed strategies on forming and sustaining an engineering ambassador program.

4. A showcase of the student's presentations occurred at the workshop's end.

5. An online community was created for discussions on sustainability and national assessment.

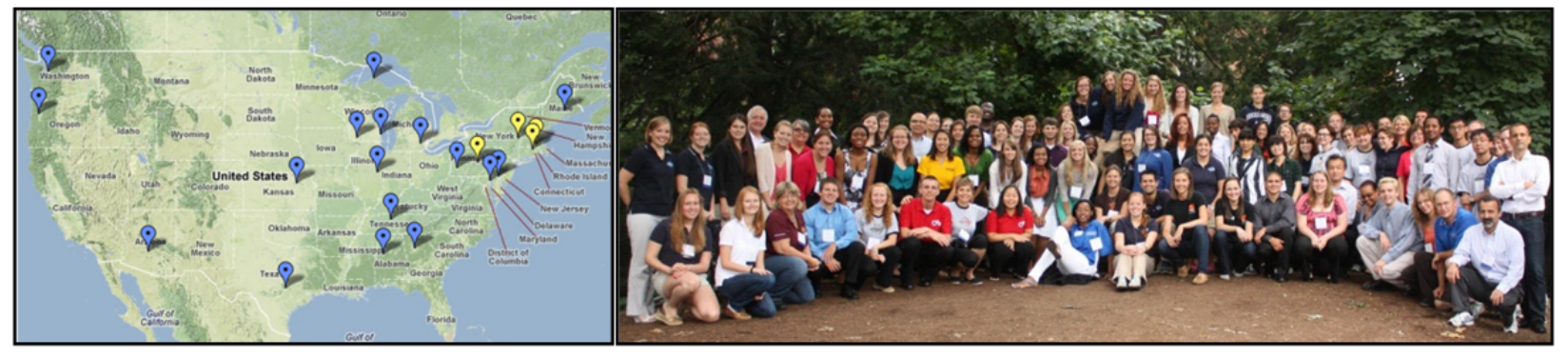

Figure 2: Participants of workshop. On the left is a map showing participating institutions: pilot programs are in blue, and member programs are in yellow. On the right is a photo of all of the attendees.

Table 1: Attending Institutions of the Inaugural Engineering Ambassador National Workshop.

\begin{tabular}{ccc}
\hline Member Schools & Pilot Schools & Pilot Schools \\
\hline Penn State & Arizona State University & The University of Texas Austin \\
RPI & Carnegie Mellon University & University of Alabama \\
University of Connecticut & Eastern Michigan University & University of Delaware \\
WPI & Georgia Institute of Technology & University of Illinois-UC \\
& Kansas State University & University of Maine \\
& Michigan Technological University & University of Washington \\
& Milwaukee School of Engineering & University of Wisconsin-Platteville \\
& Morgan State University & Vanderbilt University \\
& Oregon State University & \\
\hline
\end{tabular}

Prior to arriving at the workshop, students from each pilot institution were placed in teams of two (or sometimes three) and asked to complete preparation assignments. These assignments included reading excerpts from the National Academy of Engineering's Changing the Conversation, choosing an appropriate topic, and creating drafts of visual aids following the assertion-evidence slide structure [9-10] and using the provided templates. Experienced engineering ambassadors and faculty from Penn State provided feedback on the preparation assignments prior to the start of the workshop. During the workshop, each team continued their work to create a 15-minute presentation for school outreach visits, which they presented at the conclusion of the workshop in a showcase. Experienced engineering ambassador mentors from the four member schools were assigned to each team. The mentors worked with the teams throughout the workshop to assist them in developing their presentation. 
Pre- and post-assessments were done for those students who participated in the workshop. In short, students self-reported statistically significant improvements in a variety of presentation skills: creation of content, establishing credibility, creating effective visual aids, delivering the content, and holding the audience's attention for 15 minutes [8].

Faculty also participated in several sessions to discuss how to establish and manage an engineering ambassador program. Faculty members were introduced to the website created as a forum for future collaboration and home for the Engineering Ambassador Network:

www.engineeringambassadors.org. This site chronicles the ongoing development of the Engineering Ambassador Network and features participating programs and institutions. In addition, a Facebook page and Twitter account were created to stay in touch, share success stories, and develop a social community for the Engineering Ambassador Network.

At the inaugural national workshop, participating faculty agreed upon three defining characteristics for programs in the Engineering Ambassador Network:

1. Learning professional development skills through academically based programs.

2. Performing outreach to middle and high schools.

3. Communicating messages from Changing the Conversation. As with the student participants, the faculty participants of the Engineering Ambassador Workshop were asked to complete a pre- and post-survey. Many respondents noted that a successful engineering ambassador program will enhance skills and characteristics of the ambassadors themselves. Participants listed benefits such as communication skills, teamwork, and confidence [8].

\section{Activities in the Year Following the Inaugural National Workshop: 2012-13}

The Engineering Ambassadors National Workshop catalyzed a network of universities to begin changing the conversation about engineering. As illustrated in follow-up surveys (taken three months after the workshop), various activities on each of the pilot campuses were initiated to form engineering ambassador programs. Aiding the communication for these efforts were the web-site (www.engineeringambassadors.org) and the social media sites that we had created.

With support from the Innovation Committee of ASME [6], we held a workshop at two pilot schools (University of Illinois at Urbana-Champaign and Morgan State) in Spring 2013 to train a "critical mass" of Engineering Ambassadors on those two campuses. In addition, in the summer of 2013, the grant from the ASME Innovation Committee allowed us to hold a train-thetrainers workshop for faculty from the pilot schools to help them learn how to teach advanced presentation skills to ambassadors on their campuses. This section presents an overall assessment of those workshops and introduces the lessons learned from those experiences.

The workshops at the pilot schools showed us that the training schedule adopted for the national workshop and for the regional workshops was effective at having two- or three-person 
teams of ambassadors achieve a quality ready-to-go high school presentation by the end of the workshop weekend. In the case of one pilot school, trained ambassadors from that workshop participated in successful high school visits in the months following the workshop.

Three important lessons were learned from the two on-site workshops at the pilot schools. First, because these on-site workshops occurred during the middle of semesters or quarters, we have to deliver the preparation assignments to allow plenty of time for the students to complete them. In addition, we have to remind the students about the preparation assignments for two reasons: (1) we have not yet established credibility with these students, and (2) most students simply underestimate how much time it takes to create a strong presentation [16].

A second lesson that we learned is that it is important to verify that rooms have been reserved for the workshop, those rooms are set up properly with tables and chairs, and projection equipment and a screen are in those rooms. At one of the on-site workshops, these details were promised, but not carried out, and much valuable workshop time was spent arranging the room and finding equipment.

Yet a third lesson learned was that the ambassador cohort to be trained should be diverse. Having students from under-represented groups in the cohort is important for two reasons. First, the workshop empowers the participating students with professional skills that will help them succeed not only as ambassadors, but as professionals. For that reason, bringing in qualified students from under-represented groups provides those students with an opportunity to overcome the additional challenges that often accompany being from an under-represented group in engineering. Second, because the ambassadors will be recruiting in middle and high schools, logic dictates that sending in ambassadors from those under-represented groups will help recruit middle and high school students from those groups.

The train-the-trainers workshop, which was a 3-hour workshop held at Georgia Tech just before the 2013 ASEE Annual Conference, showed us that such a workshop could help faculty make significant progress in teaching the advanced presentation skills needed to become an ambassador in the Engineering Ambassador Network. In addition, the train-the-trainers workshop proved to be an opportunity for schools that could not participate in the inaugural national conference to learn what the Engineering Ambassador Network was about. From this train-the-trainers workshop, a number of new schools such as San Jose State University and the University of Ohio became pilot members of the Network.

From this train-the-trainers workshop, two lessons arose. First, the length of the workshop needed to be significantly longer if the instructors were to become confident at teaching the core presentation skills needed to become an ambassador in the Engineering Ambassador Network. While all of the instructors made progress at teaching those skills, most commented that they would have liked more time to learn how to teach the presentation skills, especially the assertion-evidence approach, which goes against the ubiquitous common practice of PowerPoint's defaults [17]. 
A second lesson learned was that a number of institutions simply did not have available faculty who either desired to teach or were comfortable teaching these skills. For that reason, we decided that it was important for us to provide on-line instruction to supplement the training that was being attempted at these institutions and to provide the instructors at those institutions with a teaching resource that they could study.

\section{Progress Report on First Year of Type II TUES Grant: 2013-14}

Late in the summer of 2013, we received notification of the awarding of a Type II TUES Grant from the National Science Foundation [7] for the expansion of the Engineering Ambassador Network. Soon after receiving this grant, the team notified the member and pilot schools about the grant and issued a call for proposal for pilot schools to request the hosting of an on-site workshop. Our intention was to secure four or five sites for this first-year of the grant (as promised in the proposal) so that we could begin training enough Engineering Ambassadors at those sites so that the pilot schools could move to member status.

For this call for proposals, our team created an online Workshop Proposal form to make it easier for interested institutions across the country to make submissions. Because we needed to set dates for the upcoming academic year, we established the end of September as the deadline for those proposals. By the time the deadline arrived, we received seven proposals for schools across the country from which we had to decide which schools we would visit.

Our criteria for selection included the following: whether an Engineering Ambassador program already existed in some form at the school, how much support was promised by the institution's administration, what type of facilities were available to host a workshop, what plan the institution had to insure diversity among the Engineering Ambassador candidates to be trained, and whether the institution would allow 2-4 students from other schools to participate. In this list, two of the criteria arose from lessons learned from the previous section.

After a review that included a face-to-face meeting of our advisory team, we selected five schools to receive on-site workshops for the 2013-14 academic year. These schools were University of Delaware, Ohio University, San José State University, Vanderbilt University, and Oregon State University. Because scheduling a workshop required so much lead time, all five workshops were scheduled for Spring 2014 and were to occur between February 14 and April 13, 2014.

The team has been in contact with representatives from each school to help with preparations. For instance, in December 2013, a conference call took place between our team and each school to explain in detail what the NSF TUES grant would provide for them financially, what measures they needed to take to prepare for the workshop, and to answer any of their 
questions. Each school was provided with a Workshop Checklist and Sample Workshop Weekend Schedule.

As the 2013 year comes to a close, our team is working to ensure that all five on-site workshops are successful. We are currently working with each host school to finalize an invitation list and to create a formal invitation to send out to nearby schools, inviting them to participate with a faculty member and 2-4 student participants in the workshops. Through the NSF Type II TUES Grant, funding to traveling schools will be provided for transportation and lodging. Our main goal for the on-site workshop is to train enough Engineering Ambassadors that the pilot school hosting the workshop builds a strong enough program to become a member school. A secondary goal is that other schools in the region learn about the Engineering Ambassador Network and seize this regional on-site workshop as an opportunity to become a pilot school in the Network.

In addition to our efforts to schedule on-site workshops for 2013-14, we also made progress on placing teaching materials online to help faculty at the pilot school train new recruits. For instance, we created a set of teaching materials including instructional slides with detailed teaching notes. Equally important, we created and posted online a high quality video of a sample engineering ambassador presentation [18]. This video can be viewed at www.engineeringambassadors.org.

\section{Greatest Challenges to the Network and Our Plan to Address Those Challenges}

Our team has identified the following challenge as the greatest facing the Engineering Ambassador Network in this first year of the Type II TUES grant: Maintaining the momentum and quality that the pilot schools had coming out of the inaugural national workshop. Although we will run on-site workshops at five pilot schools in 2013-14 academic year, more than 15 pilot schools will not have had an on-site workshop since they joined the Network. That means that most of the engineering ambassadors whom we trained from those schools at the inaugural national conference will have graduated before we have a chance to run a pilot workshop at those schools. Without those ambassadors at the school, we will miss an opportunity to have those ambassador help us train and mentor the incoming engineering ambassadors. In addition, without well trained engineering ambassadors on the campus, we are concerned about the quality of outreach presentations that the newly recruited, but not formally trained, engineering ambassadors will bring to the middle and high schools under the name of the Engineering Ambassador Network.

The amount of training that engineering ambassadors at the partner schools currently receive is significant. For instance, in the Engineering Ambassador Program at Penn State, students are required to enroll in a public speaking class as a part of their engineering curriculum before becoming an Ambassador. After being selected as an Ambassador, they enroll in a 3- 
credit advanced communications course during the first semester of being an Ambassador. In the advanced communication course, the Ambassadors study innovative presentation techniques, communication strategies (written and oral) for varied audiences, and emerging web communication technologies. Finally, the outreach events of the Engineering Ambassador Program provide the context and practice forum for concepts and skills learned in the course. While this model works at Penn State, a key issue in the dissemination of the Network is that other institutions do not have the required speech course to learn a foundation of presentation skills or an advanced communication course to learn the advanced presentation skills that are suited to communicating to a variety of audiences. In addition, many institutions do not have faculty who can teach these advanced engineering communication skills. Therefore, providing the communication training of ambassadors at other institutions is a key issue facing dissemination.

While our Type II TUES proposal aims to provide this training at other institutions through on-site workshops, the timing of the on-site workshops is too slow for many institutions. Most institutions want some level of training now. Moreover, once we perform an on-site workshop at an institution, that institution will want quality training the next semester for new recruits. For that reason, a key issue is for the Network to keep pace with the desires of the institutions wanting to begin their ambassador programs. To address these desires, we need to make available a basic level of support of these special communication skills to all interested institutions. Moreover, that basic level of support needs to be available whenever the institutions require it, such as the beginning of a semester when new ambassadors want training. Given these constraints, having a series of online training modules that new ambassadors can access and work through is a logical first step. Such a module will not replace the planned on-site workshops, but will allow engineering ambassador programs to make progress while waiting for an on-site workshop or another national workshop. Our team has experience creating such modules to teach principles of engineering writing - as an example, please see http://www.engr.psu.edu/mediaportal/wce/engineering writing/1d/. Given that, we will leverage this experience to create modules of similar quality for the training needed in the Engineering Ambassador Network.

To create these online training modules and to make sure that they fulfill the needs of the pilot schools, we have proposed a plan through the NSF I-Corps Program. These modules will not only teach the essential presentation principles of the Engineering Ambassador Network, but also quiz the participants on their understanding of those principles. In addition to helping the engineering ambassadors being trained, the modules will stand as a teaching resource for the faculty members at each site who have the responsibility of ensuring that engineering ambassadors sent to give outreach presentations at middle and high schools are indeed ready. 


\section{Acknowledgments}

We wish to thank the National Science Foundation and the American Society for Mechanical Engineers (ASME) for their support of this work. In particular, the inaugural national workshop for the Engineering Ambassadors in 2012 was supported by National Science Foundation Grant 0835875. In addition, the five on-site workshops discussed are being supported by Type II TUES Grant 1323230 from the National Science Foundation. Finally, the three pilot workshops that occurred in 2013 were supported by an Innovation Grant from ASME.

\section{References}

1. Carnevale, A.P. and S.J. Rose (2011). The Undereducated American. Available at http://www9.georgetown.edu/grad/gppi/hpi/cew/pdfs/undereducatedamerican.pdf

2. American Society of Engineering Education (2009). Available at http://www.asee.org/papers-andpublications/publications/college-profiles/2009-profile-engineering-statistics.pdf. Accessed October $1,2011$.

3. ASME (2010). Vision 2030-Creating the Future of Mechanical Engineering Education. American Society of Mechanical Engineers. New York.

4. National Academy of Engineering (2008). Changing the Conversation: Messages for Improving Public Understanding of Engineering. Washington, D.C.: NAE Press.

5. Karen A. Thole, Mary Frecker, Michael Alley, and Sarah Zappe (2009). Communicating what mechanical engineers do: A strategy for recruiting women. National Science Foundation Grant 0835875. Department of Mechanical Engineering, Penn State, 2009-2010.

6. Innovation Committee, American Society of Mechanical Engineers and ASME Foundation (2013). Engineering Ambassador Network. New York: ASME.

7. Karen A. Thole, Michael Alley, Melissa Marshall, and Joanna K. Garner (2013). Type II: Creating a national network of engineering ambassadors: A professional development program with an outreach mission. National Science Foundation Grant, TUES Program, 1323230. College of Engineering, Penn State, 2013-2016.

8. President B. Obama (2012). http://www.asee.org/papers-and-publications/news-andsurveys/news/press-releases/president-s-council-on-jobs-and-competitiveness-to-host-deans-ofengineering-announce-new-partnership-with-asee

9. Karen A. Thole, Melissa Marshall, Michael Alley, and Sarah Zappe (June 2013). Engineering Ambassador Network: Dissemination through an inaugural national workshop. 2013 ASEE Annual Conference. Atlanta, Georgia: American Society of Engineering Educators.

10. Michael Alley (2013). The Craft of Scientific Presentations, $2^{\text {nd }}$ ed. New York: Springer-Verlag. 
11. Joanna Garner and Michael Alley (2013). How the design of presentation slides affects audience comprehension: A case for the assertion-evidence approach. International Journal of Engineering Education, vol. 29, no. 6, pp. 1564-1579.

12. North Carolina State University Engineering Ambassadors (2012). Available at http://students.engr.ncsu.edu/ambassadors/index.php. Accessed October 1, 2012.

13. Purdue University Engineering Ambassadors (2012). Available at https://engineering.purdue.edu/Intranet/Groups/Programs/Ambassadors. Accessed October 11, 2012.

14. Cornell University Engineering Ambassadors (2012). Available at http://ea.cornell.edu/index.cfm. Accessed October 8, 2012.

15. Texas Tech University Engineering Ambassadors (2012). Available at http://www.depts.ttu.edu/coe/ambassadors/. Accessed October 9, 2012.

16. Richard Feynman (1985). Surely, You're Joking Mr. Feynman! New York: Norton, p. 171.

17. Traci Nathans-Kelly and Christine Nicometo (2014). Slide Rules: Design, Build, and Archive Presentations in the Engineering and Technical Fields. New York: Wiley-IEEE Press.

18. Lauren Murphy and Sarah Krisher (2013). Taking engineering to new heights. https://www.vimeo.com/ 73537143. University Park: Penn State. 